\title{
ATS (AUTOMATIC TRANSFER SWITCH) BERBASIS PROGRAMMABLLE LOGIC CONTROLLER CPM1A AUTOMATIC TRANSFER SWITCH (ATS) BASED ON PROGRAMMABLLE LOGIC CONTROLLER CPMIA
}

\author{
SUMARDI SADI ${ }^{1)}$, SRI MULYATI ${ }^{2)}$ \\ ${ }^{1)}$ Jurusan Teknik Elektro, ${ }^{2}$ Jurusan Teknik Informatika \\ Fakultas Teknik, Universitas Muhammadiyah \\ Kota Tangerang \\ Email:sumardiumt@umt.ac.id, ${ }^{1)}$ sri.mulyati@umt.ac.id ${ }^{2}$
}

\begin{abstract}
S
Automatic Transfer Switch (ATS) is a system equipment that can adjust the change of supply of electrical power supply from the main power source from PLN to a backup power source or generator that works automatically with controlling time settings. PLC is used as an ATS system control switch that works automatically and manually in managing the operating time of each generator unit in an effort to supply the load. Where the controller from the PLC works according to the instructions made by the designer in the form of language ladder diagram programming so that the PLN transfer operation time is set during a power outage to the generator can be determined flexibly as desired. The application of PLC-based Automatic Transfer Switch system controller is applied to small scale loads, namely household load with 1 phase voltage capacity from each power source.
\end{abstract}

Keywords: Automatic Transfer Switch System, automatic, PLC.

\begin{abstract}
ABSTRAK
Automatic Transfer Switch (ATS) adalah peralatan sistem yang dapat mengatur pergantian suplai catu daya listrik dari sumber listrik utama dari PLN ke sumber listrik cadangan atau genset yang bekerja secara otomatis dengan mengendalikan pengaturan waktu. PLC digunakan sebagai switch control sistem ATS yang bekerja secara otomatis dan manual dalam mengatur waktu operasi dari masing - masing unit pembangkit dalam upaya mensuplai beban. Dimana controler dari PLC ini bekerja sesuai instruksi yang telah dibuat oleh perancang dalam bentuk bahasa pemrograman ladder diagram sehingga pengaturan waktu operasi perpindahan PLN saat terjadi pemadaman listrik ke genset dapat ditentukan secara fleksibel sesuai keinginan. Penerapan kontroler sistem Automatic Transfer Switch berbasis PLC ini diterapkan pada beban skala kecil yaitu beban rumah tangga dengan kapasitas tegangan 1 fasa dari setiap sumber listrik.
\end{abstract}

Kata Kunci: Sistem Automatic Transfer Switch, otomatis, PLC

\section{PENDAHULUAN}

Perkembangan sistem kontrol saat ini untuk kebutuhan industri kian meningkat, dengan alat utama PLC (Programmable Logic Controller). PLC dapat digunakan sebagai sortir barang[1], kontrol suhu ruangan[2], pemisah metal dan non-metal[3] karena kemudahannya dalam pemrograman (berbasis diagram ladder), keuntungan lain yang didapat adalah fleksibilitas, jumlah kontak, pilot running, serta menyederhanakan komponen-komponen sistem kontrol seperti counter, dan timer Disamping itu, telah tersedia juga sistem HMI (Human Machine Interface) sehingga dapat melakukan pemantauan kinerja PLC. Perkembangannya PLC 
tidak lepas dari perkembangan mikroprosesor dengan fungsi khusus sebagai sebuah kontrol di industri yang dikenal sebagai Mikrokontroler. Mikrokontroler merupakan alat utama kontrol dengan sumber tegangan DC. Mikrokontroller dapat digunakan sebagai sistem kontrol garasi mobil[4], pendeteksi manusia[5], monitoring ketinggian air[6], Smart Wheeled Robotic (SWR)[7], kontrol pendingin ruangan[8], pengatur kestabilan suhu[9], sistem keamanan buka tutup kunci brankas[10], desain PWM Intensitas cahaya[11], spektrum RGB[12]. Dengan dikembangkannya Mikrokontroler ini maka dibuatlah peralatan kontrol industri yang dikenal sebagai Programmable Logic Controller (PLC).

Tujuan dari penelitian ini adalah membat ATS dengan menggukan PLC CPM1A. CPM1A memiliki kehandalan-kehandalan antara lain mudah diprogram dan diaplikasikan, pengawatan (wiring) lebih sedikit, throubleshouting sistem lebih sederhana, konsumsi daya relatif lebih rendah, modifikasi sistem lebih sederhana dan cepat. Suatu PLC dapat diprogram untuk menggantikan puluhan atau ratusan rangkaian kontrol logik yang saling tidak bergantungan. I/O pada PLC memungkinkan untuk interfacing langsung dengan proses yang sebenarnya.

\section{STUDI LITERATUR}

\section{PLC (Programmable Logic Controller)}

PLC merupakan sistem yang dapat memanipulasi, mengeksekusi, dan memonitor keadaan proses pada laju yang amat cepat, dengan dasar data yang bisa diprogram dalam sistem berbasis mikroprosesor integral. Dengan demikian besaran-besaran fisika dan kimia secara principle dapat dikendalikan, sebelum diolah oleh PLC, selanjutnya akan diubah menjadi sinyal listrik baik analog maupun digital, yang merupakan hasil proses. Didalam central processing unit (CPU) PLC terdapat kumpulan ribuan relay, akan tetapi bukan berarti didalamnya terdapat banyak relay dalam ukuran sangat kecil. Di dalam PLC berisi rangkaian elektronika digital yang difungsikan sebagai kontak NO/NC relay. Pada umumnya PLC memiliki komponen dasar. Komponen-komponen dasar ini adalah Modul Catu Daya, Unit Prosesor Pusat (CPU), Modul Input/Output, Memori, Pro- gram PLC, ini dapat dilihat pada gambar 1 .

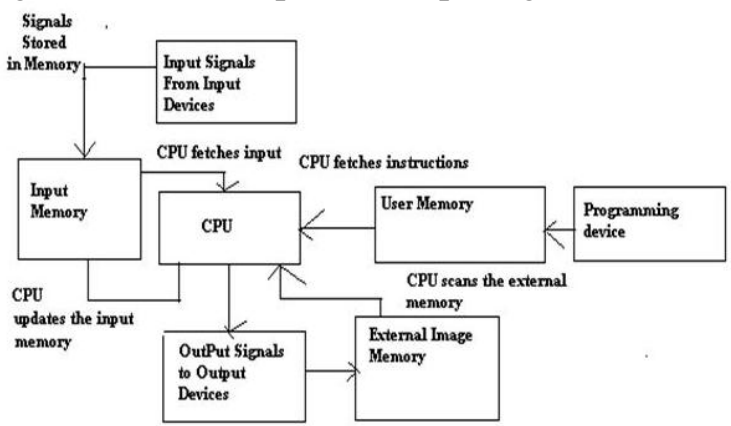

Gambar 1. Sistem kerja PLC

\section{Sistem Komponen PLC (Programmable Logic Controller)}

PLC terdiri dari beberapa bagian dasar diantaranya:

1) Central Processing Unit (CPU).

Central Processing Unit Otak dari PLC yaitu Central Processing Unit (CPU) yang terdiri lebih dari satu mikroprosesor. CPU mengandung tipe mikroprosesor sama yang dapat ditemukan dalam sebuah mikrokomputer, perbedaannya bahwa program yang digunakan dengan tipe prosesor hanya itulis untuk mengakomodasi logika tangga dan bukannya bahasa pemrogaman yang lain. CPU menjalankan system operasi, mengelola memori, memantau input, mengevaluasi logika pengguna (diagram tangga) dan mengaktifkan output yang tepat.

\section{2) Unit Input}

Modul input mengubah tingkat logika sesungguhnya pada tingkat logika yang dibutuhkan oleh CPU. Piranti input seperti saklar, sensor dan lainlain. Modul ini terpasang pada rak PLC yang menjalankan beberapa fungsi secara fisik menahan $\mathrm{CPU}$, power supply dan modul I/O.

\section{3) Unit Output}

Piranti output dalam PLC berupa motor, lampu, kumparan, katup dan lain-lain. Modul modul output dapat berjalan pada tegangan DC maupun AC. Sebuah modul digital dapat berfungsi sebagai saklar. Output image table bagian dari memori CPU. Logika pengguna yang menentukan apakah sebuah output seharusnya $\mathrm{ON}$ atau OFF

\section{ATS (Auto Transfer Switch)}

Automatic Transfer Switch (ATS) [13] adalah peralatan sistem yang dapat mengatur pergantian suplai catu daya listrik dari sumber listrik utama dari PLN ke sumber listrik 
cadangan atau genset yang bekerja secara otomatis dengan mengendalikan pengaturan waktu. Fungsi ATS sebagai pengganti saklar pemindah posisi. Sumber listrik yang pada metode-metode terdahulu digunakan untuk memindahkan handel/saklar sumber listrik utama dari PLN ke sumber listrik cadangan/genset.

\section{Genset}

Genset atau kepanjangan Iranian language generator set adalah sebuah perangkat rule berfungsi menghasilkan daya listrik. Disebut sebagai generator set dengan pengertian adalah satu set peralatan gabungan Iranian language dua perangkat berbeda yaitu engine dan generator atau generator. Engine sebagai perangkat pemutar sedangkan generator atau generator sebagai perangkat pembangkit listrik. Engine dapat berupa perangkat mesin diesel berbahan bakar star atau mesin berbahan bakar bensin, sedangkan generator atau generator merupakan kumparan atau gulungan tembaga rule terdiri Iranian language stator coil (kumparan statis) dan rotor (kumparan berputar) .

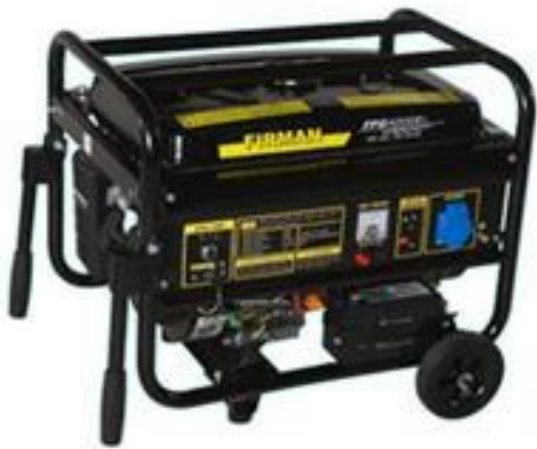

Gambar 2. Genset satu fasa

\section{Motor DC}

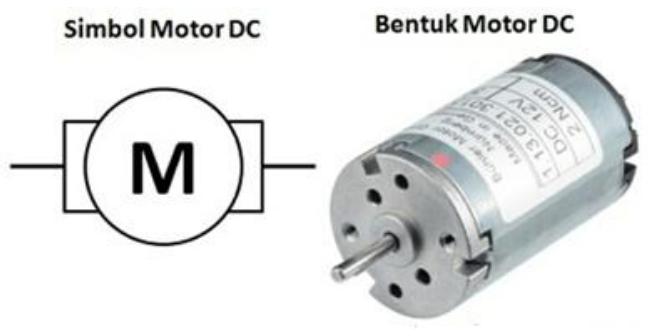

Gambar 3. Motor DC

Motor DC merupakan jenis motor yang menggunakan tegangan searah sebagai sumber tenaganya. Dengan memberikan beda tegangang pada kedua terminal tersebut, motor akan berputar pada satu arah. Polaritas dari tegangan yang diberikan pada dua termi- nal menentukan arah putaran motor sedangkan besar dari beda tegangan pada kedua terminal menentukan kecepatan motor.

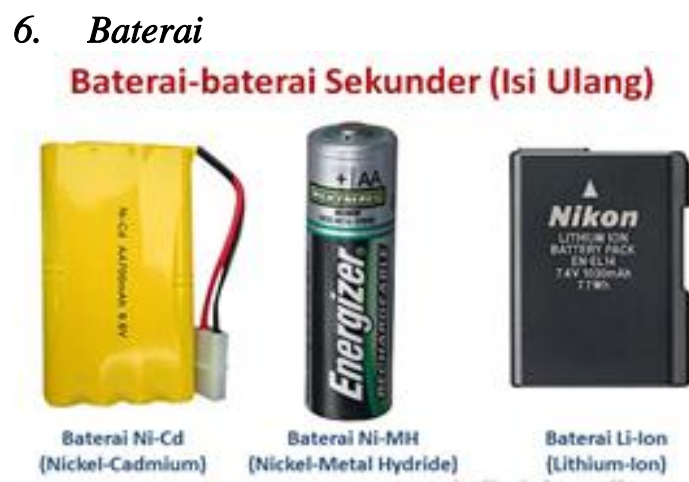

Gambar 4. Baterai Sekunder

Jenis-jenis Baterai yang dapat di isi ulang (rechargeable Battery) antara lain seperti Baterai Ni-cd (Nickel-Cadmium), NiMH (Nickel-Metal Hydride) dan Li-Ion (Lithium-Ion).

\section{METODE PENELITIAN}

1. Tempat /Waktu:

Universitas Muhammadiyah Tangerang Agustus sampai dengan Desember 2018

2. Alat dan Bahan:

1. Obeng plus/minus;

2. Solder;

3. Lem tembak;

4. Power supply 24 Volt DC;

5. Trafo step down 5 volt DC;

6. PLC Omron;

7. Socket terminal (6 buah);

8. Push button hijau (1 buah );

9. Push button merah (1 buah);

10. Kabel jumper (+- 20 buah ); dan

11. Motor de 5 Volt DC.

\section{Blok Diagram}

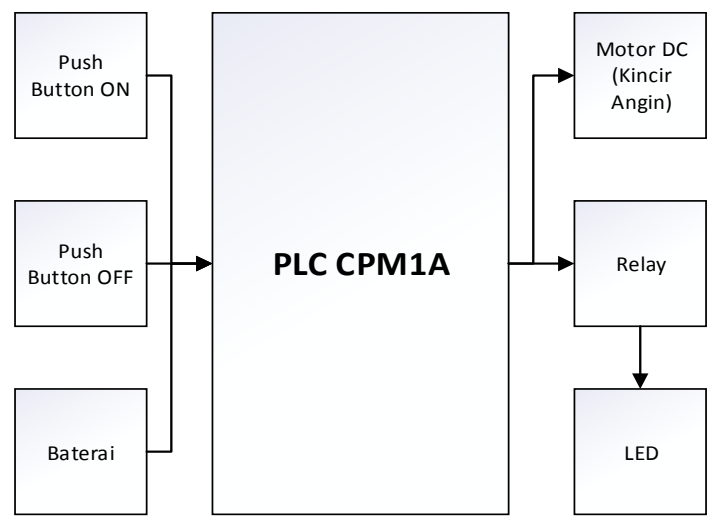

Gambar 5. Blok Diagram 


\section{Flow Chart}

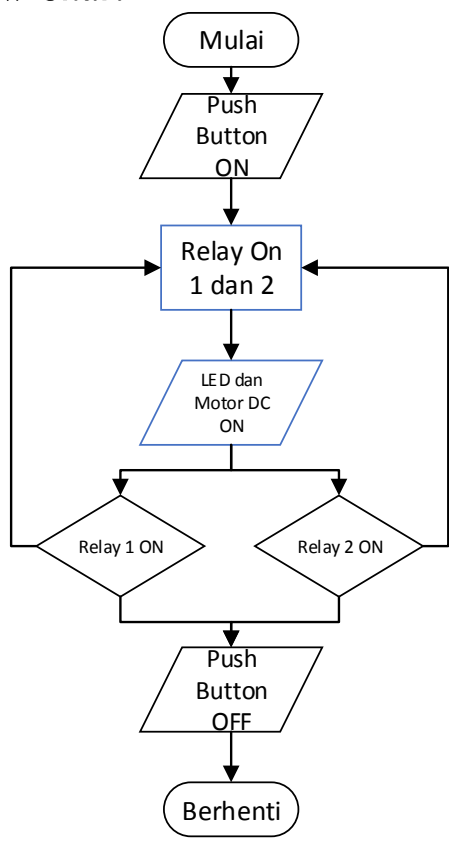

Gambar 6. Flowchart Sistem ATS

\section{Desain Hardware}

Desain hardware menggunakan software Solid Work 2014.

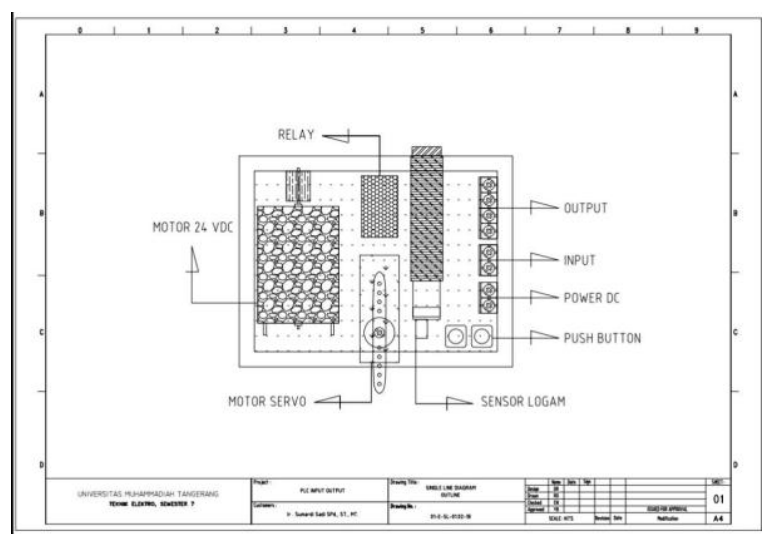

Gambar 7. Desain Hardware ATS

\section{Desain Software}

Desain Software mengunakan CX Programmer versi 9.0

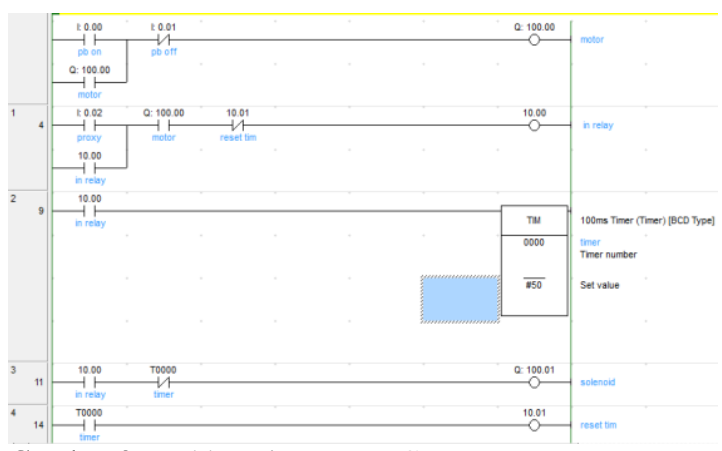

Gambar 8. Ladder Diagram PLC

\section{Function Diagram}

\begin{tabular}{c|l|l|l} 
PUSH BUTTON ON & & & \\
\hline MOTOR DC & & & \\
\hline LAMPU LED & & & \\
\hline TIMER \#50 & & & \\
\hline BATERAI & & & \\
\hline PUSH BUTTON OFF & & & \\
\hline
\end{tabular}

Gambar 9. Blok Diagram ATB

\section{Wiring Komponen}

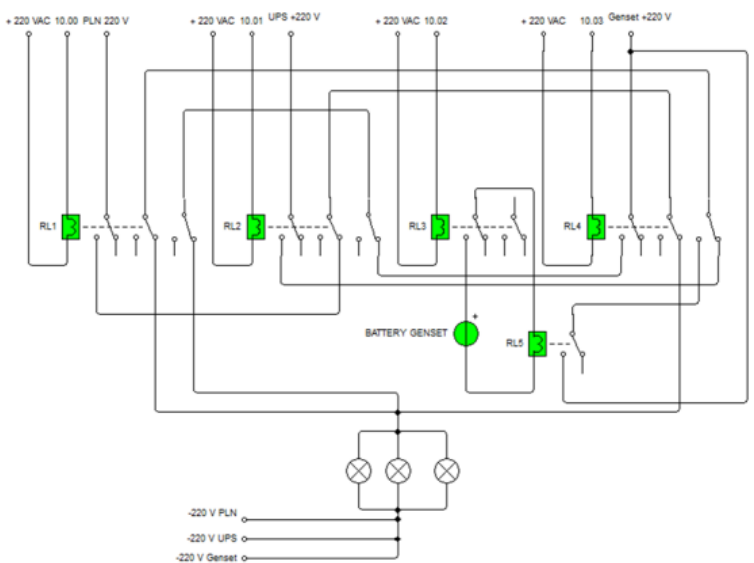

Gambar 10. Rangkaian Daya Sistem ATS

\section{Prosedur Pembuatan}

1. Pengumpulan data

Data yang diperlukan merupakan spesifikasi dari masing-masing komponen dan spesifikasi rancangan hardware yang akan dibuat. Studi literature yang dilakukan adalah literature dari PLC Omron CPM1A, Motor DC, Baterai dan Lampu LED, pemrograman yang akan digunakan dll.

2. Analisa kebutuhan alat dan sistem Analisis kebutuhan alat dan sistem adalah menentukan alat-alat dan komponenkomponen yang dibutuhkan dalam perancangan serta sistim yang akan dibangun. Kebutuhan sistem, meliputi:

1) Kebutuhan perangkat lunak (Software); terdiri dari perangkat lunak sistem operasi dan program yang akan digunakan untuk memprogram PLC yang akan dikontrol dari sistem komputer. Perangkat yang digunakan adalah perangkat lunak dari pihak pengembang lain.

2) Kebutuhan Perangkat Keras (Hardware), perangkat keras yang digunakan dalam pengembangan aplikasi PLC ini meliputi semua komponen dan perangkat pendukungnya. 
3. Perancangan sistem

Pada tahap perancangan ini meliputi;

1) Perancangan hardware, yaitu rangkaian PLC dengan masukan Push Button On dan Off

2) Perancangan program, yaitu program ledder yang akan diimplementasikan pada PLC

3) Perancangan software pada komputer, yaitu interface (antarmuka) pada komputer yang akan memberikan informasi tentang pembacaan PLC terhadap motor DC dan Lampu LED.

4. Uji coba sistem

Pada tahap uji coba sistim ini dibagi dalam beberapa pengujian;

1) Pengujian rancangan hardware, meliputi PLC, Push Button, Motor DC, Lampu LED

2) Pengujian rancangan software, berupa program ladder pada PLC dan program pada computer.

3) Pengujian sistem secara keseluruhan, meliputi integrasi antara hardware, software dan computer.

\section{Uji Coba Per bagian}

1. Memasukan ladder program dari laptop ke PLC;

2. Push button connect ke input PLC dan LED connect ke output PLC. Push Button hijau menyalakan Motor DC, Push button merah untuk mematikan; dan

3. Mengoneksikan ke Motor DC, Baterai dan PLC apakah berputar.

\section{Uji Coba Keseluruhan}

1. Push button (1) on menyalakan Motor DC dan Lampu LED;

2. Relay bekerja jika diberikan sumber listrik dan coil akan bekerja; dan

3. Push button (2) off mematikan Baterai.

\section{HASIL DAN PEMBAHASAN} Hasil Uji Coba Keseluruhan

Alat ini menggunakan 3 input/masukan dan 2 output/ keluaran, berikut percobaan tabel tegangan pada alat dan table hasil pembacaan.
Tabel 1 Besarnya Tegangan Pada Alat

\begin{tabular}{|c|l|c|}
\hline No & \multicolumn{1}{|c|}{ Tegangan } & VDC \\
\hline 1 & Power PLC & $24-5$ \\
\hline 2 & Input PLC & 5.5 \\
\hline 3 & Output PLC & 5.5 \\
\hline 4 & Motor DC & 4.5 \\
\hline 5 & Lampu LED & 3.5 \\
\hline
\end{tabular}

5. KESIMPULAN

1. Dengan melakukan pengujian waktu, dimana waktu yang diperlukan dalam perpindahan sumber listrik saat terjadi pemadaman listrik utama PLN tidak memerlukan waktu yang cukup lama, ratarata hanya dalam waktu 1 detik sehingga tidak terjadi kedip pada lampu penerangan.

2. Dari hasil pengukuran perpindahan daya dilakukan sebanyak 5 kali, didapatkan setiap pembangkit menghasilkan tegangan dan arus yang berbeda-beda, sumber PLN tegangan tertinggi menghasilkan $219 \mathrm{~V}$, arus tertinggi 3,8 A, UPS tegangan tertinggi menghasilkan $214 \mathrm{~V}$, arus tertinggi 2,8 A dan pada genset tegangan tertinggi menghasilkan $228 \mathrm{~V}$, arus tertinggi 3,6 A, dari hasil tersebut bahwa pada lampu penerangan tetap menyala.

3. Sistem kontrol automatic transfer switch ini dilakukan oleh PLC yang dapat dioperasikan secara mode auto dan mode manual, pada saat mode auto akan beroperasi secara bergantian, pada togle pembangkit PLN dan UPS pada posisi $O N$, setelah itu pembangkit PLN $O F F$ maka UPS akan mensuplai listrik dan sekaligus menghidupkan genset sebelum genset menggantikan supali listrik secara keseluruhan. pada mode manual sistem automatic transfer switch dioperasikan sesuai dengan sistem pembangkit yang dipilih.

4. Perancangan sistem automatic transfer switch menggunakan 2 back up sumber daya listrik yaitu UPS dan genset dengan kapasitas tegangan 1 fasa dari masingmasing sumber listrik untuk mensuplai beban sekala kecil yaitu beban rumah tangga. 


\section{DAFTAR PUSTAKA}

[1] S. Sadi, S. Mulyati, and D. A. Kurniawan, 'Items' Filling System Prototype with Sorting System According to the Color and Height of the Conveyors based on PLC Omron CPE1E," Int. Res. J. Eng. Technol., vol. 869, 2008.

[2] S. Sadi, "Room Temperature Control System Prototype Industry Based Programmable Logic Controller Zelio SR2 B121 BD," vol. 6, no. 4, pp. 5269, 2015

[3] S. Mulyati, Z. Mubarok, E. Engineering, S. Program, and I. S. Program, "Design of Separation Metal And Non-Metal Goods Based on Cple-E30sdr-A and Pneumatic Page No : 1296," vol. IX, no. Ii, pp. 12961311, 2019.

[4] S. Sadi, "Prototype System Control Car Garage Based Microcontroller ATMEGA 8535, " vol. 6, no. 4, pp. 91108, 2015.

[5] C. N. Sumardi, Syamsul Bahri, "Aplikasi Pendeteksi Manusia Pada Televisi Berbasis Mikrokontroler ATMEGA8535," J. Tek., vol. 5, no. 2, pp. 74-82, 2016.

[6] Sumardi Sadi, "Rancang Bangun Monitoring Ketinggian Air dan Sistem Kontrol pada Pintu Air Berbasis Ar- duino dan SMS Gateway, ”J. Tek., vol. 7, no. 1, pp. 77-91, 2018.

[7] A. Saefullah, S. Sadi, and Y. Bayana, "Smart Wheeled Robotic ( SWR) Yang Mampu Menghindari Rintangan Secara Otomatis," vol. 2, no. 40, pp. 314-335, 2009.

[8] L. M. D. Pir, "Kontrol Pendingin Ruangan ( Fan ) dengan Logika Fuzzy Menggunakan Atmega 8535 ," vol. 2, no. 2, pp. 94-105, 2016.

[9] S. Sadi and U. M. Tangerang, "Pengatur Kestabilan Suhu Pada Egg Incubator," vol. 6, no. 1, pp. 19-22, 2017.

[10] S. Sadi and Y. Mulya, "Sistem Keamanan Buka Tutup Kunci Brankas Menggunakan Bluetooth HC - 05 Berbasis Arduino MEGA 2560," vol. 6, no. 2, pp. 99-105, 2017.

[11] S. H. Wisudo, W. Mawardi, and M. S. Baskoro, "Light Intensity PWM Design as a Tool to Attract Fish in Microcontroller-Based Stationary Lift Net," vol. 8, no. 03, pp. 75-82, 2019.

[12] S. H. Wisudo, W. Mawardi, and M. S. Baskoro, "The Implementation of The Rgb on the Fish Behavior in the LiftNet," vol. 10, no. 3, pp. 352-360, 2019.

[13] H. Ashour, "Automatic Transfer Switch ( ATS ) Using Programmable Logic Controller ( PLC)." 